\title{
Design and implementation of bi-directional converter with internet of things control based reading
}

\author{
Wisam Dawood Abdullah' ${ }^{1}$, Raad Z. Homod ${ }^{2}$, Abdulbasit H Ahmed ${ }^{3}$ \\ ${ }^{1}$ Cisco Networking Academy, Tikrit University, Tikrit, Iraq \\ ${ }^{2}$ Department of Oil and Gas Engineering, Basrah University for Oil and Gas, Iraq \\ ${ }^{3}$ Electrical Engineering Department, Engineering College, Tikrit University/Iraq
}

\begin{tabular}{l} 
Article Info \\
\hline Article history: \\
Received Apr 25, 2021 \\
Revised Jun 13, 2021 \\
Accepted Jun 25, 2021 \\
\hline Keywords: \\
Bidirectional DC-DC converter \\
Buck/boost converter \\
ESP-12E Wi-Fi module \\
Internet of things \\
PWM
\end{tabular}

\begin{abstract}
In this paper, a new technique to monitor and control bidirectional DC-DC converter was designed and implemented precisely. A prototype of a complete system is verified with efficient communication capabilities. This system is realized by integrating the internet of things (IoT) operating system and the bidirectional DC-DC converter. The IoT communication facilities further develop and extend the platform for this system. The DC-DC converter with the soft switching technique will then convert the battery voltage to a high voltage of $380 \mathrm{~V}$ inverter bus in emergencies via boost converter mode. High-frequency toroidal transformer has been used for power level shifting and isolation between the primary and secondary sides of the transformer. The closed-loop control scheme is implemented in software by using a high-performance 32-bit STM32 microcontroller. IoT technique is used to find current, voltage and perform the communication smoothly through Wi-Fi sensors to complete the design of the system. The results of the proposed system prove the effectiveness of the proposed system with high-performance specifications.
\end{abstract}

This is an open access article under the CC BY-SA license.

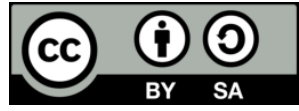

\section{Corresponding Author:}

Wisam Dawood Abdullah

Computer Science Department

Computer Science and Mathematics College

Tikrit University, Iraq

Email: wisamdawood@tu.edu.iq

\section{INTRODUCTION}

The smart utilization of power systems increased with the increase of the Internet of things (IoT) as one of the available solutions to integrate renewable energy sources, especially the solar cell with the conventional power stations [1]. The electrical and thermal power generation techniques are increased in different areas and for many applications such as solar, wind, nuclear, and fossil [2]. IoT and wireless sensor networks were considered to be one of the most widely improved fields in the last decade [3]. Different technologies have been improved for these two items. It is very important to have a robust and stable power source. The advances in technology offer a solution to any problem like the instability and vary with the environmental conditions in the energy applications, especially the solar power that varies with environmental conditions. Hence, it is important to have high-performance for the converters, transformers, and rechargeable batteries [4]. Thus, a precise management of power system is one of the most crucial demands for stable and efficient operation of the control systems [5]. There is a wide variety of the DC-DC converters such as buck, boost, or buck/boost converters [6]. In the power systems, the bidirectional transformation of power is required between load DC and the battery in many applications such as home 
hybrid inverters, energy storage banks or uninterruptible power supply (UPS), to avoid power being interrupted to the load.

In the normal operation, the $\mathrm{DC}$ bus is driven from the rectified $\mathrm{AC}$ main or from conditioning the voltage of a renewable source of energy like solar panels or wind power generator. The battery can be charged through either the grid voltage or the renewable external source of energy [7]. Normally, this is done with two unidirectional converters, one converter to charge the battery from DC bus (normally, a buck converter) and another converter for converting the battery voltage and feeding it to the DC bus (boost converter) in the discharging mode [8]. In conventional systems, two power converters are used both of which is in one direction. Hence, more cost, space and complexity will be added to the system [9]. Bidirectional DC-DC converters can combine two unidirectional converters into a single converter, this will allow a bilateral power flow between the battery and the load [10].

In normal mode, the DC bus works in buck mode and charges the battery from the HV DC bus at a constant current until the battery's voltage reaches the limit. During the DC bus interruption, the designed system works in the boost mode full-bridge converter to boost the voltage from the $48 \mathrm{~V}$ battery to the $380 \mathrm{~V}$ DC bus and backs up the load from a power outage. During the DC bus presence, the design operates in buck mode and charges the battery with constant current until the battery voltage is within regulated limits.

In the blackouts case, the design operates as the current-fed full-bridge converter to boost the power from a 48-V battery (44 - 56) V input voltage to the $380 \mathrm{~V}$ DC bus to support the load backup. The variation during the operation period must guarantee the continuity of power to the load [11]. The system response of about $200 \mu \mathrm{s}$, which significantly reduces the DC bus capacitors, is required to maintain the voltage at an acceptable level during the operation period. The designed system with a very low $\mathrm{R}_{\mathrm{ds}}$ (on) resistance of MOSFETs that has been used in the LV section achieves maximum efficiency of $88 \%$ in charger mode and $92 \%$ in the battery discharge mode [12]. Besides, it allows more battery run time and less emitted heat [13]. The $\mathrm{R}_{\mathrm{ds}}(\mathrm{on})$ is referred to as the static drain-source on the resistance of the MOSFET. An amorphous nanocrystalline transformer core with very high permeability and high saturation induction yields a much simpler winding procedure with very few turns even with lower switching frequencies [14]. More robustness and current capabilities than available High voltage MOSFET's are obtained in the HV side by using $20 \mathrm{kHz}$ low switching frequency transformer and IGBT's transistors [15]. Non-Isolated Bidirectional Dc/Dc Converter (NIBDC) and Isolated Bidirectional Dc/Dc Converter (IBDC) are the two types of Bi-directional $\mathrm{dc} / \mathrm{dc}$ converter on the basis of galvanic isolation provided between input and output. There are many topologies of isolated converters such as forward fly back, dual push-pull, dual fly back, Dual-CUK, dual half-bridge, and dal active full-bridge IBDC.

The major NIBDC topologies are bidirectional buck-boost converter, cascaded bidirectional buckboost converter, bidirectional CUK converter, bidirectional SEPIC-ZETA Dc/Dc converter, switched capacitor bidirectional Dc/Dc converter, interleaved non-isolated bidirectional Dc/Dc converter, 2-phase interleaved [16]. With a Wi-Fi sensor in the circuit, it is a very powerful tool to measure the system's current, voltage, and power. Using remarkable advances in IoT, big data and addressing the critical issue of increasing the device service life under a fixed and limited energy source through receiving and sending the current, voltage, errors, and status of the system [17].

This proposed system presents an IoT microcontroller-based isolated bidirectional converter of 2 $\mathrm{kW}$ of output power. The operation in buck mode charges $48 \mathrm{~V}$ gel-type, HV DC bus interruption. The converter operates in boost mode, converting the $48 \mathrm{~V}$ battery voltage to $380 \mathrm{~V}$ used as a backup source of $\mathrm{DC} / \mathrm{AC}$ inverter connected to HV side. The contribution of this work is an improved design of such a converter that has been designed to distribute the power from a 48V battery to (300-380) V DC bus with the use of full-bridge IGBT power stage on HV side, isolated from a full-bridge MOSFET power stage on the LV side with IoT based reading. To avoid the current ripple, the leakage inductance of the transformer, and electromagnetic interference, a soft-switching technique is used to avoid the shortcomings of the conventional bidirectional converters and prove its feasibility using this converter. The organization of this paper is as follows; section 1 gives an introduction. Hardware implementation is available in section 2. Section 3 introduces control side implementation. The experimental results are provided in section 4. Finally, section 5 summarizes the conclusions of this work.

\section{HARDWARE IMPLEMENTATION}

The first power stage of the designed system is the HV stage, which consists of an IGBT-based fullbridge to act as a step-down converter in charging mode and works as a full-bridge that is rectifier in the boost mode. The 400V DC bus voltage stepped down using a high-frequency amorphous transformer with galvanic capability of isolation between primary and secondary. The HV stage primary side of the full-bridge is driven with a phase shift modulation technique to obtain zero voltage switching (ZVS). This will help for the minimization of the turn-on switching losses of the primary switches. 
Unlike the traditional PWM that operates in hard switching mode and many injected harmonics leads to a significant reduction of power [18], [19]. Therefore, the phase-shifted full bridge is more suitable for high frequency and power applications [20]. The power stage diagram of the designed system is shown in Figure 1.

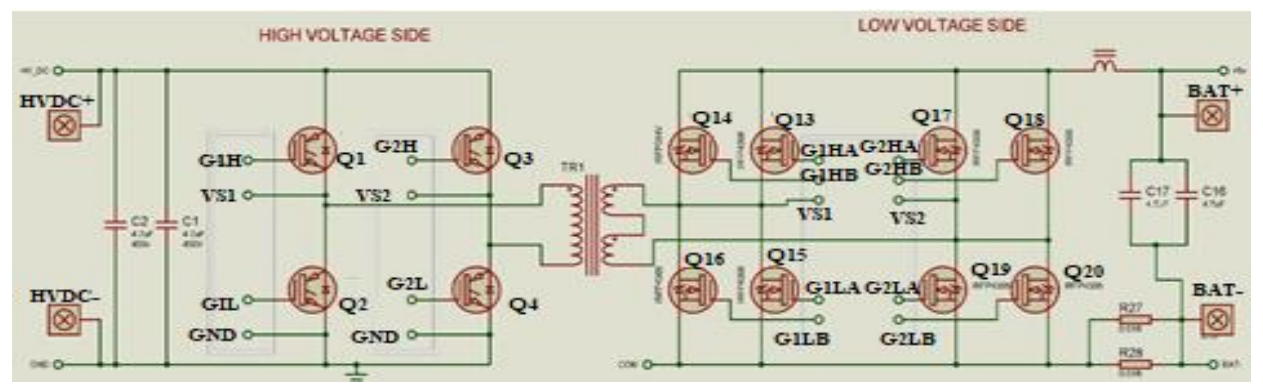

Figure 1. Power stage schematic of the designed system

Two complementary PWM signals drive each leg of the primary side converter (Q1 and Q2, Q3 and Q4) at a fixed 50\% duty cycle. The phase shift angle between the two legs of the bridge determines the duty cycle of the bipolar voltage applied to the primary or the induced voltage on the transformer's secondary voltage. The implementation of phase-shifted modulation is obtained by delaying the two complementary square waves of the second leg (Q3 and Q4) concerning the reference square wave of the first leg (Q1 and Q2) and (Q3 and Q4) for the leading-leg (Q1 and Q2) [21], [22] as explained in Figure 2.

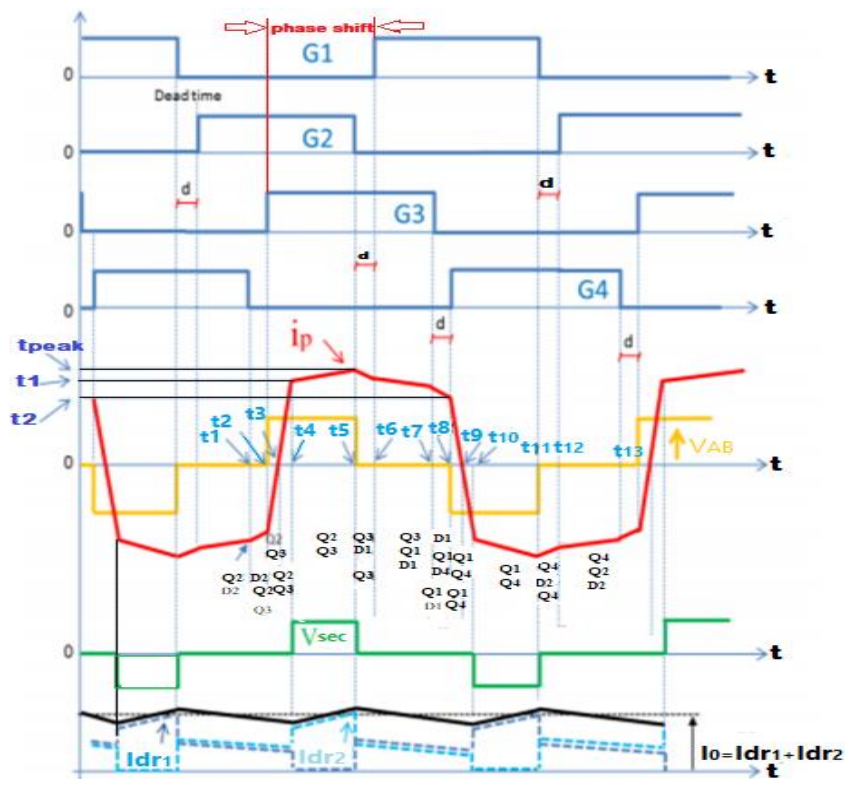

Figure 2. Gate signals, primary transformer current, and voltage of the primary side

Dead time of $1 \mu \mathrm{sec}$ inserted between Q1-Q2 and Q3-Q4 is one of the limits to avoid cross conduction and reduce the errors during the transition time. The controller is responsible for adjusting the phase angle according to the required battery voltage. The traditional ferrite-based cores require a very high number of turns (typically 300 turns) compared to the amorphous Fe-based Nanocrystalline core that has been used in this design. According to the core datasheet, it requires 22 turns at $400 \mathrm{~V}$ Vbus only in the primary side at the same frequency [23], [24]. The transformer turns ratio for the designed system can be calculated using (1) [7].

$$
N_{\text {pri }} / \mathrm{N}_{\mathrm{sec}}=\left(V_{\mathrm{in}_{\min }}\right) /\left(V_{\text {out }_{\max }}\right) * \delta_{\max }
$$


Where Nsec is the secondary turn's number, Npri is the primary turn's number, and $\delta$ max is the maximum duty cycle appearing at the transformer secondary winding at one switching period. In the designed system, another important factor of the limitation parameters is the maximum duty cycle, which is estimated as $\delta_{\max }=0.8$. This is very important in the reduction of the duty cycle loss, dead time of the driving signals. The selected transformer core is $\mathrm{T} 56^{*} 28 * 28$, according to the manufacturer, and it is capable of delivering power between (2-3) kilowatts. The maximum phase shift which is determined by the control loop can be calculated from:

$$
N_{\text {pri }} / \mathrm{N}_{\text {sec }}=V_{\text {in }_{\text {min }}} / V_{\text {out }_{\text {max }}}=300 / 56 * 0.8 \approx 4.3: 1
$$

The transformer's primary (HV side) must be designed to withstand the maximum bus voltage. According to the manufacturer's datasheet, the number of turns for the primary side at $30 \mathrm{kHz}$ switching frequency and the $400 \mathrm{~V}$ input voltage is equal to 22 turns; therefore, the secondary turn is equal to $22 / 4.3 \approx 5$ Turns. Two groups of the secondary windings were added in parallel and distributed regularly around the core to increase the mutual inductance between the primary and secondary, as shown in Figure 3.

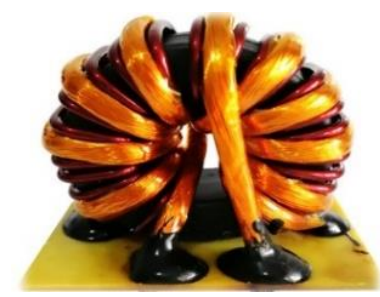

Figure 3. The final form of the transformer

The range of the high voltage (HV-side) DC bus voltage is (300-380) V, while the range of the secondary low voltage is (44-56) V. This converter can be easily modified for different system requirements by changing the amorphous transformer turns ratio and few software parameters as another powerful issue of this work. The output power stage (LV stage) of the designed system consists of a MOSFET based full bridge. Each leg of the bridge includes two MOSFET's in parallel to increase the current capabilities of the converter and to increase the overall efficiency of the system. The increasing efficiency is satisfied by reducing the amount of heat generated by the low voltage side switches due to the higher flowing current.

In backup mode or boost mode, the designed system boosts the battery voltage in range (44-56) $\mathrm{V}$ to $350 \mathrm{~V} \mathrm{DC}$ output. The topology that is suitable for this purpose is either a voltage-fed or a current-fed converter. The voltage-fed has the input capacitors connected across the power stage and an output inductor. The voltage-fed topology has several advantages over the current-fed converter: The boosted input voltage reduces the stress on the transformer; avoiding imbalance of the flux, which is presented in the current fed converter in the power stage and reduce the stress on the input capacitors because of the inductor. However, the voltage-fed converter is not suited for the charger mode because the filter capacitors are connected directly after the low voltage side's full-bridge. The variation in the phase shift of the input (varying the phase shift in the HV side) produces a variable duty cycle on the LV side. This does not alter the output voltage because the output filter capacitors are being rapidly charged during the on-time.

During the off-time, the output filter capacitors conserve a considerable amount of charge, especially with a light load connected. Hence, the output voltage is still at the same level or slightly changes, even when varying the phase-shifted angle between 0 and 180 degrees. The varying output voltage is essential with buck mode so, the voltage-fed topology is not suitable for the designed system despite its several advantages in boost mode. The designed system has been chosen to be a current-fed converter in boost mode while it works as a voltage-fed buck converter when working in charger mode.

In charger mode, the converter transfers the power from the primary (HV side) DC bus, also it charges the $48 \mathrm{~V}$ battery pack using four $12 \mathrm{~V} / 150 \mathrm{AH}$, gel-type solid-acid, deep-cycle batteries in series in constant current/constant voltage $(\mathrm{CC} / \mathrm{CV})$ mode. The charging current is another limiting factor, which is limited by software to $20 \mathrm{~A}$. The low voltage (LV) side in charging mode works as a synchronous rectifier to enhance the system's efficiency. The MOSFETs used in the secondary side (LV) have an extremely low onresistance, and thus, their conduction losses are very low compared to the diode's rectifier. As mentioned before, the low voltage side of the designed system has MOSFET doubled to increase current capability. IRFP4468 MOSFET with $\left(\mathrm{V}_{\mathrm{dss}}=100 \mathrm{~V}, \mathrm{R}_{\mathrm{ds}}(\mathrm{on}) \leq 2.6 \mathrm{~m} \Omega\right.$ and $\left.\mathrm{I}_{\mathrm{d}}=195 \mathrm{~A}\right)$ has been selected due to its extremely low resistance and high current ability, which has made it a good solution for such a converter. 
In Figure 1, each diagonally positioned transistor in the low voltage side (Q5A, Q5B, Q8A, and Q8B) are turned on and off simultaneously with the primary transistor Q1. Similarly, the other diagonal transistors (Q6A, Q6B, Q7A, and Q8B) synchronized in gate drive signals with the HV transistor Q2. Indicating that the MOSFET of output stage is always synchronized with the first leg of the high voltage side (Q1 and Q2). Figure 4 shows a sample of the waveform of $90^{\circ}$ phase shift angle between the first leg (Q1 and Q2) and the second HV leg (Q3 and Q4).

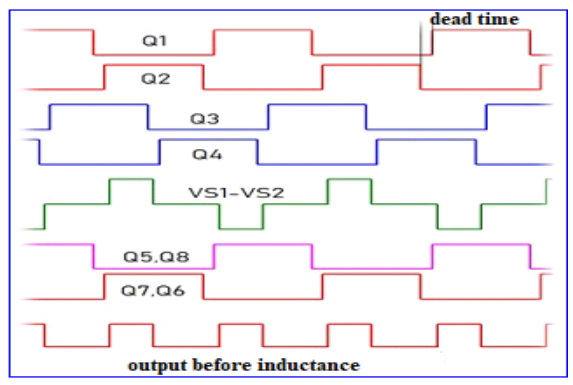

Figure 4. Waveforms for all transistors (HV and LV) in charger mode with $90^{\circ}$ phase shift

In boost mode, the high voltage side transistors are turned off because synchronous rectification does not benefit when using IGBT's. This is due to the turn-on voltage of the IGBT (VCE) is larger than its internal freewheeling diode's forward voltage of about $2.5 \mathrm{~V}$. This value is the saturation voltage of the IGBT compared to the $1 \mathrm{~V}$ forward voltage for the diode. Therefore, if the high voltage IGBTs are turned off in boost mode, the built-in four diodes in each IGBT will form a full-bridge diode. This rectifier is used to rectify the transformer's alternating voltage and smooth by the HV side filter capacitors to power the DC bus.

The maximum voltage of the input battery when fully charged $\mathrm{V}_{\text {bat } \max }=56 \mathrm{~V}$. The maximum was appearing voltage across the transformer's primary winding must be chosen to be higher than this voltage to maintain the boost action. For achieving a minimum boost ratio, the voltage on the low voltage side ( $\mathrm{V}_{\text {PRI }}$ ) is given in (2).

$$
V_{P R I}=1.1 V_{\text {bat } \max }=61.6 \mathrm{~V}
$$

By selecting the $\mathrm{V}_{\text {PRI }}=61.6 \mathrm{~V}$, a sufficient voltage margin can be maintained on the $100 \mathrm{~V}$ MOSFET on the low side. A MOSFET type (IRFP4468) is preferred in the design to control the voltage spikes at turnoff caused by the current-fed inductor.

A relatively $30 \mathrm{kHz}$ low switching frequency has been selected for the best operating frequency range for the amorphous transformer and IGBT's. This will help to minimize the switching losses on both sides of the converter and maintain high efficiency. Zero voltage switching (ZVS) in boost mode reduces electromagnetic interference (EMI). Hence, a high efficiency of $90 \%$ is obtained. Micro-seconds $(200 \mu \mathrm{S})$ switchover from charging with $88 \%$ efficiency to backup mode with $92 \%$ efficiency helps reduce highvoltage hold up capacitor requirements. It is considered as an important factor for increasing the efficiency. The maximum battery input power $\mathrm{P}_{\mathrm{IN} \text { max }}$ is given in (3) [25].

$$
P_{I N_{\max }}=P_{\text {out }} \text { max } / \text { efficiency }=2000 / 0.9=2222.2 \mathrm{~W}
$$

The minimum usable voltage for the $48 \mathrm{~V}$ battery pack is set to $44 \mathrm{~V}$ to avoid the completely drained batteries. The maximum average input current IIN max will be as in (4).

$$
I_{I N_{\max }}=P_{I N_{\max }} / V_{B A T_{\min }}=2222.2 / 44=50.5 \mathrm{~A}
$$

The inductor $\left(\mathrm{L}_{1}\right)$ calculation procedure is similar to the one that has been used for the boost converter. The maximum allows inductor ripple percentage $\left(\mathrm{I}_{\mathrm{IN} \max \text { ripple }}\right)$ and the maximum period of all the MOSFET's full-bridge in the LV side are on simultaneously ( $\mathrm{V}_{\mathrm{PRI}}$ ). To find $\mathrm{D}_{\text {max }}$ overlab, $\mathrm{D}_{\max }$ needs to be calculated by (5):

$$
V_{\text {pri }}=V_{\text {bat }_{\text {min }}} /\left(1-D_{\text {max }}\right)
$$

This yield 


$$
\mathrm{D}_{\max }=1-\mathrm{V}_{\text {bat min }} /\left(2 \mathrm{~V}_{\text {pri }}\right)=0.643
$$

$\mathrm{D}_{\text {max_over lab can be calculated from (6) }}$

$$
D_{\text {max } \_ \text {overlab }}=D_{\max }-0.5=0.143
$$

By setting the inductor ripple to $40 \%$, the $\mathrm{I}_{\mathrm{IN} \text { max }}$ riple can be found from (7)

$$
I_{I N_{\text {max } \text { riple }}}=I_{I N_{\max }} * 0.4=20.2 \mathrm{~A}
$$

Finally, $\mathrm{L}_{1}$ can be calculated from (8).

$$
L_{1}=V_{\text {bat }_{\text {min }}} * D_{\text {maxoverlab }} /\left(I_{\text {max }_{\text {riple }}} * F_{S w}\right)=10.4 \mu H
$$

To wind this inductor, the peak inductor current $\mathrm{I}_{\mathrm{IN} \text { peak }}$ needs to be calculated by (9).

$$
I_{I N \text { peak }}=I_{I N \max }+I_{I N \text { max riple }} / 2=60.6 A
$$

The inductor of the current-fed converter should have a toroidal core with material that has low loss, relatively high saturation level, and capable of operating at high frequencies. Kool $\mathrm{Mu}$ is a very popular material that is ideally suited for this type of applications. The part number of the toroidal core used is the Micrometals Arnold's MS-157060-2 with a permeability of 60 and a nominal AL value of $81 \mathrm{nH} / \mathrm{N}^{2}$, where $\mathrm{A}_{\mathrm{L}}$ is the inductance factor or inductance per square of turns is the characteristic for a given magnetic core (type, size, air gap, etc.) provided by the manufacturer.

For a $10.4 \mu \mathrm{H}$ coil, the DC magnetizing force $(\mathrm{H})$ should be less than this core limit. For verifying such value, the number of turns which is required to obtain the required inductance at maximum input current $\mathrm{I}_{\mathrm{INpeak}}=60.6 \mathrm{~A}$. The DC energy storage in the inductor is $(10)$.

$$
J=0.5 L I^{2}=0.5 * 10.4 \times 10^{-6} *(60.6)^{2=} 19096 \mu J
$$

From the DC energy/storage-NI (ampere-turns) curve in the datasheet results in the NI is about 1200 ampere-turns. Using this value to find the load current drops to $25 \mathrm{nH} / \mathrm{N}^{2}$ as in Figure 5. Hence, the required number of turns is equal to (11).

$$
\mathrm{N}=(\mathrm{N} \times \mathrm{I}) / \mathrm{I}=1200 / 60.6 \approx 20 \text { Turns }
$$

The duty cycle of each leg is constant at approximately $50 \%$ due to the phase-shifted full bridge in the high voltage. The ideal solution for this problem is to use a transformer with one primary and two separates, identical, $180^{\circ}$ out of phase and isolated secondary windings with turns ratio of 1:1:1 for driving the legs [26], [27] as shown in Figure 6.

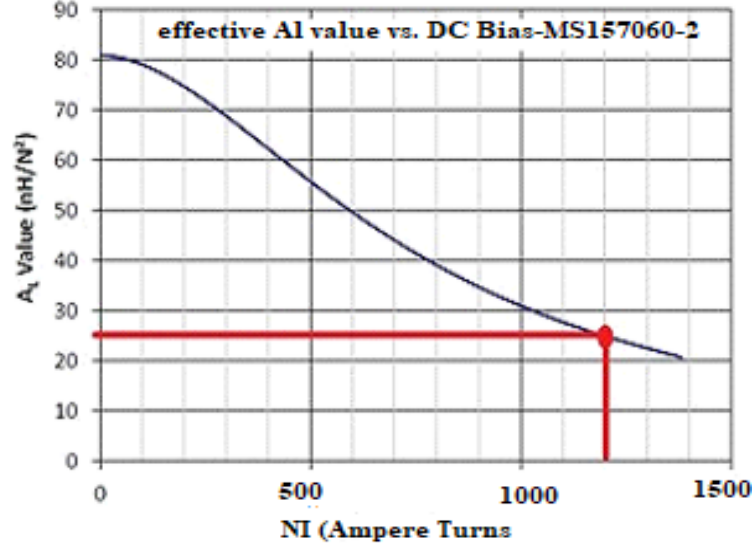

Figure 5. Inductance factor with the NI relationship

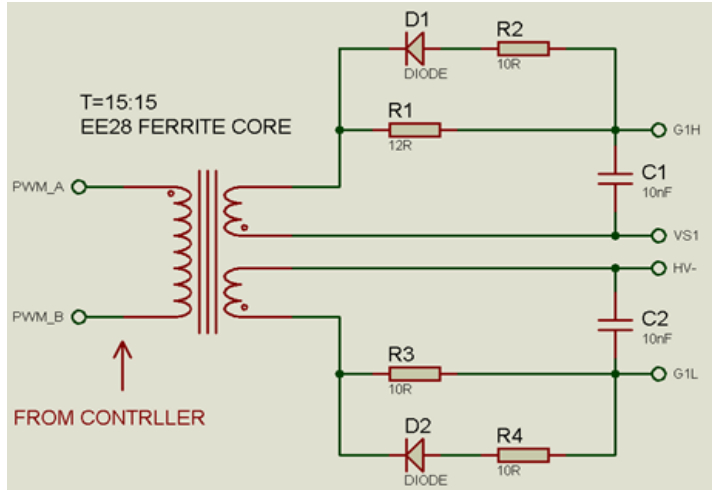

Figure 6. Transformer gate driver for each leg of the HV side transistors 
The gate transformer primary windings are supplied with bipolar PWM signals from the microcontroller. Transistor will be ON state during the duration of the pulse. Meanwhile, the lower transistor turned off because of the negative voltage applied to its gate due to reversed polarity. The gate driver transformer primary windings are less than the number of turns of the secondary $(1: 3: 3)$ to achieve the IGBT gate driver requirements [25].

The principle of operation is the same for the HV side and the low voltage side, but MOSFETs require less gate voltage to be turned ON. Unlike the MOSFET, a $10 \mathrm{~V}$ is not enough for the gate driver transformer. The gate driver transformer needs to be boosted with $5 \mathrm{~V}$ from the controller to $10 \mathrm{~V}$. The LV side gate driver has a turn's ratio of 1:2:2: 2:2. The gate driver transformers for the HV side and LV side is shown in Figure 7.

More system flexibility is obtained due to the ability to change the ratio of the gate driver pulse transformer [28]. The power circuit contains two full-bridge transistors in both low and high sides, power transformer, capacitor smoothing filters in the filter input/output, and an inductor on a low-voltage side. All components are integrated into one single printed circuit board. Hence, the improvement of the thermal stability of the system is obtained. The Proteus design software is used in the fabrication.

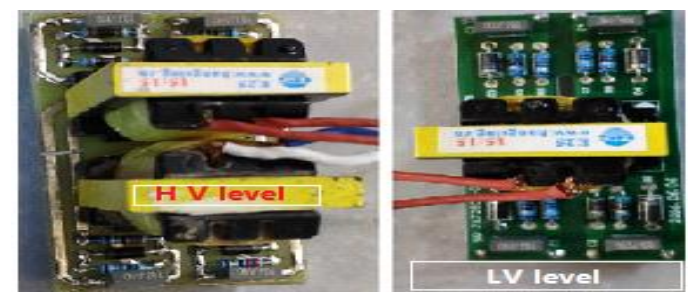

Figure 7. Gate driver transformers for the HV and LV sides

\section{CONTROL SIDE IMPLEMENTATION}

The control loop includes two loops, an inner current loop sampling frequency (Fs) of $25 \mathrm{kHz}$ and the outer voltage loop with $\mathrm{Fs}=197 \mathrm{~Hz}$. The high sampling rate $(25 \mathrm{kHz})$ very important in the protection and accidental short circuits. The inner current loop controls the ac side inductor current in phase with the supply voltage so a high-power factor can be achieved. The voltage loop is important to control the voltage of the dc-link through the PI controller. The PI controller has the following objectives: 1) to increase the working efficiency, and 2) to provide the pulse to the IGBT's. The control structure is shown in Figure 8.

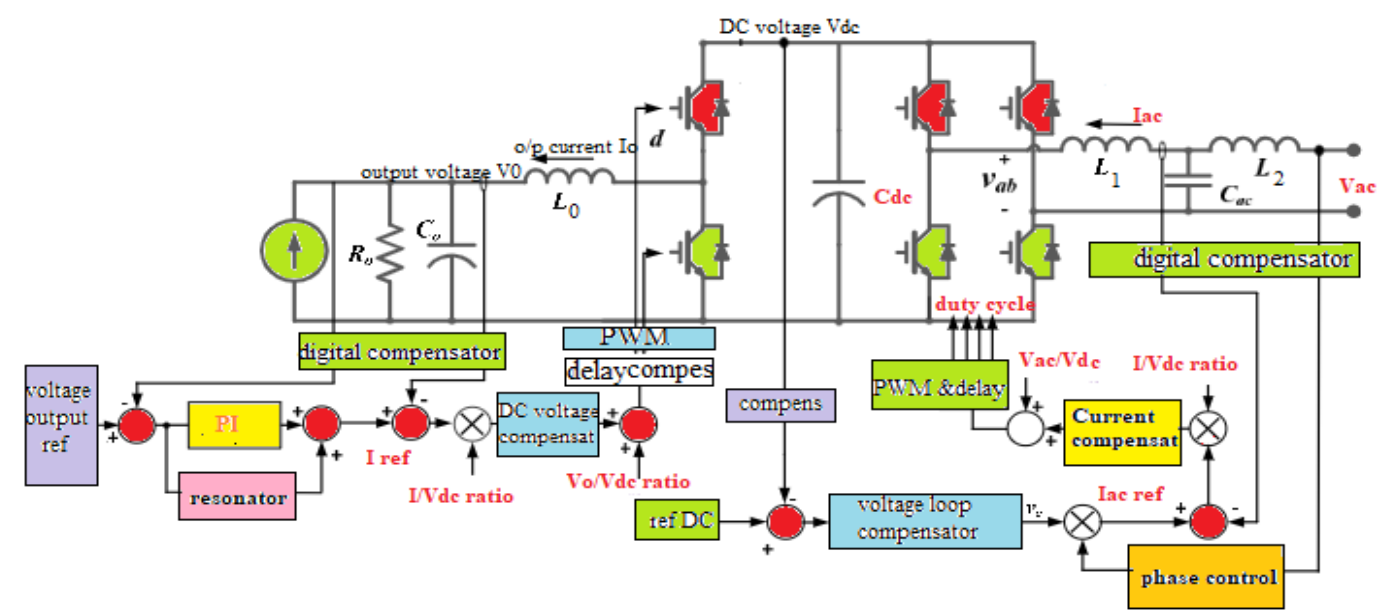

Figure 8. Complete bidirectional control loops

The PID controller is not used in this work since; the PI controller-based filter is easily applicable in practice to adjust the phase shift of the output voltage. The switching frequency can be selected low, and it is sufficient for STM32F030K6T6 Microcontroller switching capabilities. From Figure 8, the PI controller's action can be summarized as follows.

a) To measure the value of output voltage. 
b) To compare the output voltage with the desired output voltage.

c) To set the reference current and providing a trigger signal to DC voltage compensator to generate the PWM signal of the IGBT's.

The STM32F030K6T6 Microcontroller from ST microelectronics is used. The block diagram of the complete work can be shown in Figure 9. CoIDE is used as a free integrated development environment software for microcontrollers. The microcontroller software is used to implement and control battery charging [29]. The first one is to control the output voltage/current, running at $50 \mathrm{kHz}$; the second loop is for compensation of the output-boosted voltage running at $10 \mathrm{kHz}$ [30]. The over-voltage and over current for both power stages used digital compensators. Duty cycles with delays control the MOSFETs according to the PWM generated signals. The communications between the computer and the system via IoT as new techniques for speed, safety. ESP-12E Wi-Fi module are used in this work with core processor ESP8266 in smaller to integrates industry-leading ultra-low-power 32-bit MCU micro, with the 16-bit short mode. This module is added to an existing bidirectional DC/DC converter under the standard IEEE802.11 b/g/n agreement, complete TCP/IP protocol stack. The pin configurations of the ESP-12E are shown in Figure 10.

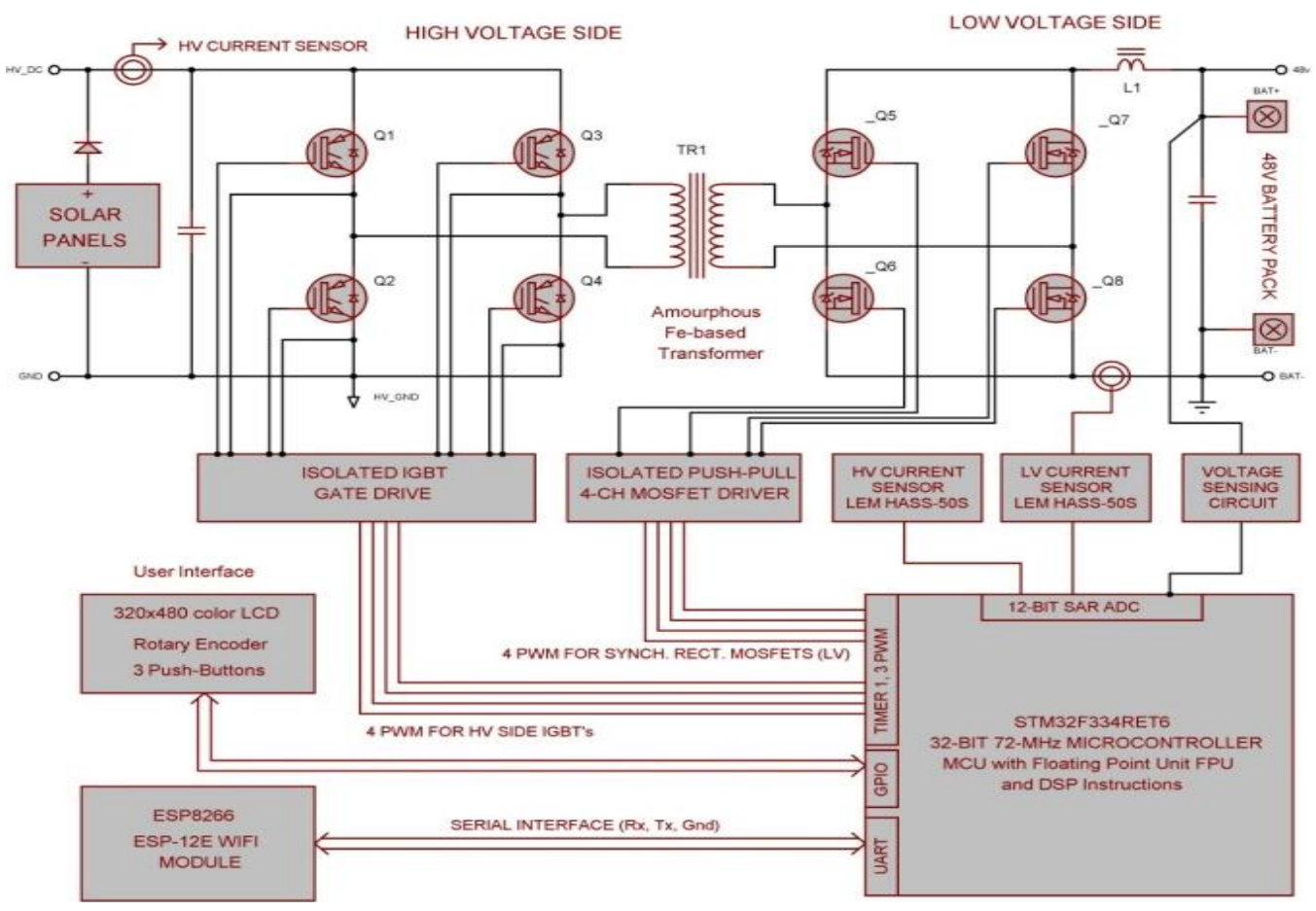

Figure 9. Block diagram of the proposed work

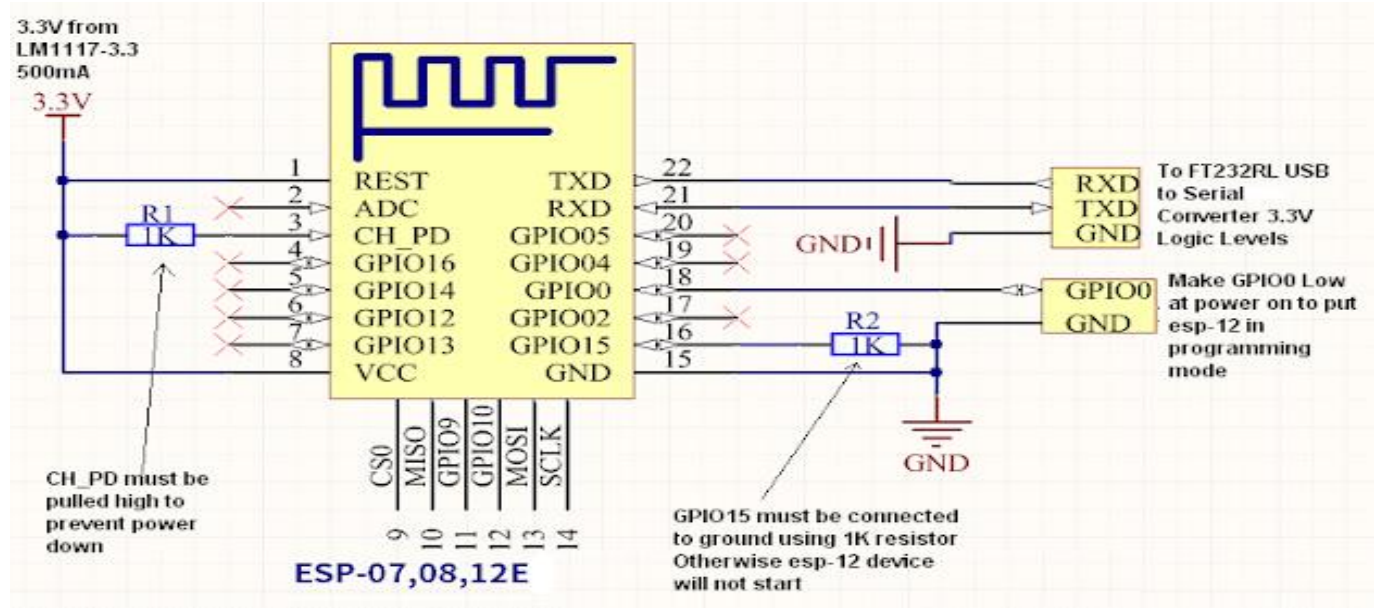

Figure 10. Pin configuration of ESP-12E Wi-Fi module 
The STM32F030K6T6 microcontroller sends the required data to a predefined internet server using Wi-Fi. MCU provides a combination of functionality of having both input and output ports the same as the microcontroller and Wi-Fi module. The microcontroller performs all the calculations necessary, whereas ESP8266 provides the functionality of communication via Wi-Fi. The flowchart of the presented work is shown in Figure 11. IoT is a powerful tool with renewable energy sources [31].

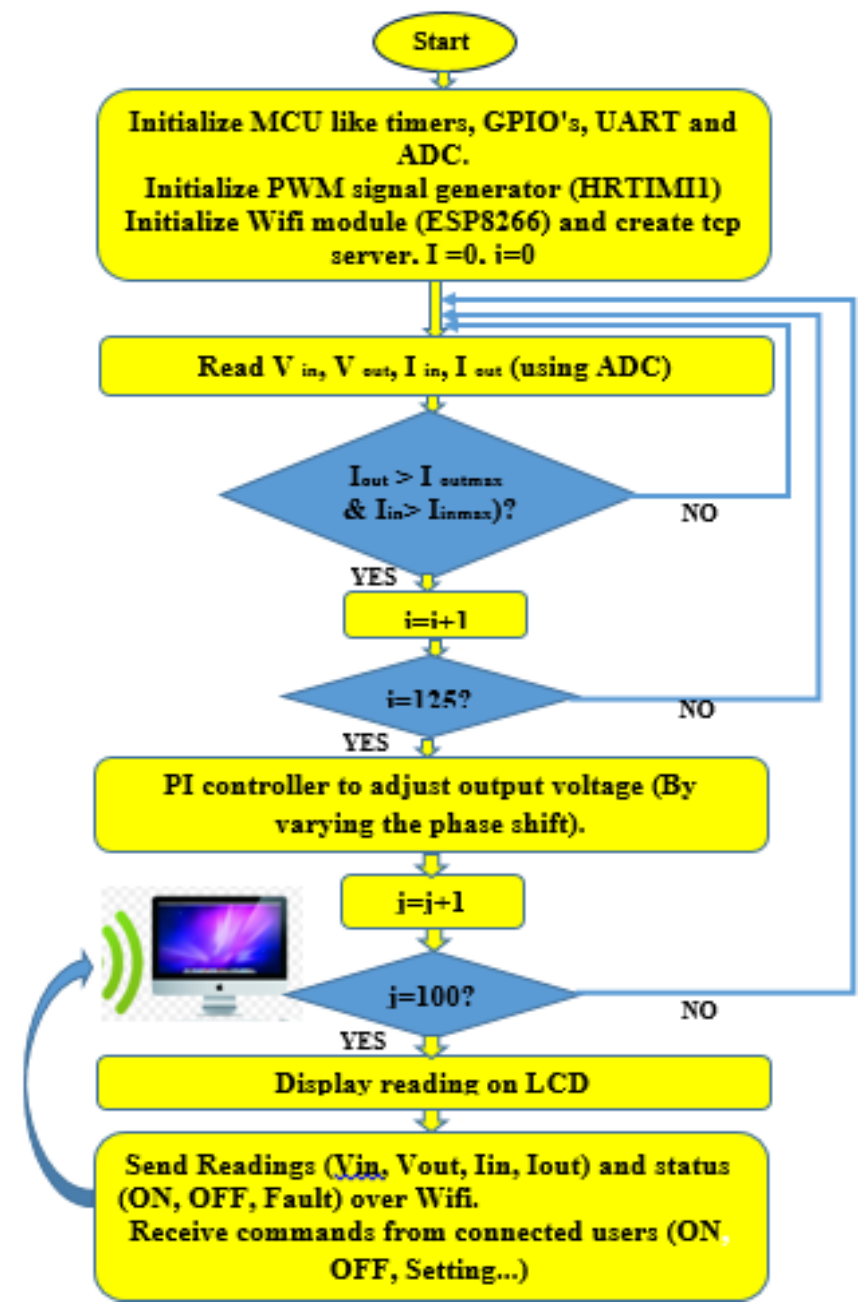

Figure 11. Flowchart of the complete work

\section{EXPERMINTAL RESULTS}

The complete system verification is shown in Figure 12. The 320 VDC input voltage that has been rectified from AC mains of 230 VAC. Setting point of $49 \mathrm{~V}$ output voltage in software to get full rated power and high efficiency of $92 \%$ at full load. The final experimental setup is shown in Figure 13.

The operating output voltage of $49 \mathrm{~V}$ with capacitor voltage between $30 \mathrm{~V}$ to $44 \mathrm{~V}$. The load power demand varies up to $\mathrm{P}_{\max }=2222.2 \mathrm{~W}$. The systems and storage batteries' energy consists of typical low voltage type batteries with wide voltage and power ranges. The smooth switching and PI controller are very active in this context. Hence, the efficiency-optimized isolated bidirectional DC-DC converter with high voltage and current is between (20-50) A diversity. The maximum efficiency is obtained at full power $(2 \mathrm{~kW})$ as shown in Figure 14.

Complementary PWM signals with dead time supplied from the microcontroller to each leg of the bridge Q1\& Q2 are shown in Figure 15. The same signal after the driver board, measured between the transistor's gate and emitter terminal, is shown in Figure 16. The voltage waveform across the transformer's primary terminals at a phase shift of $60^{\circ}$ are shown in Figure 17. The key specifications of the designed system are listed in Table 1. 


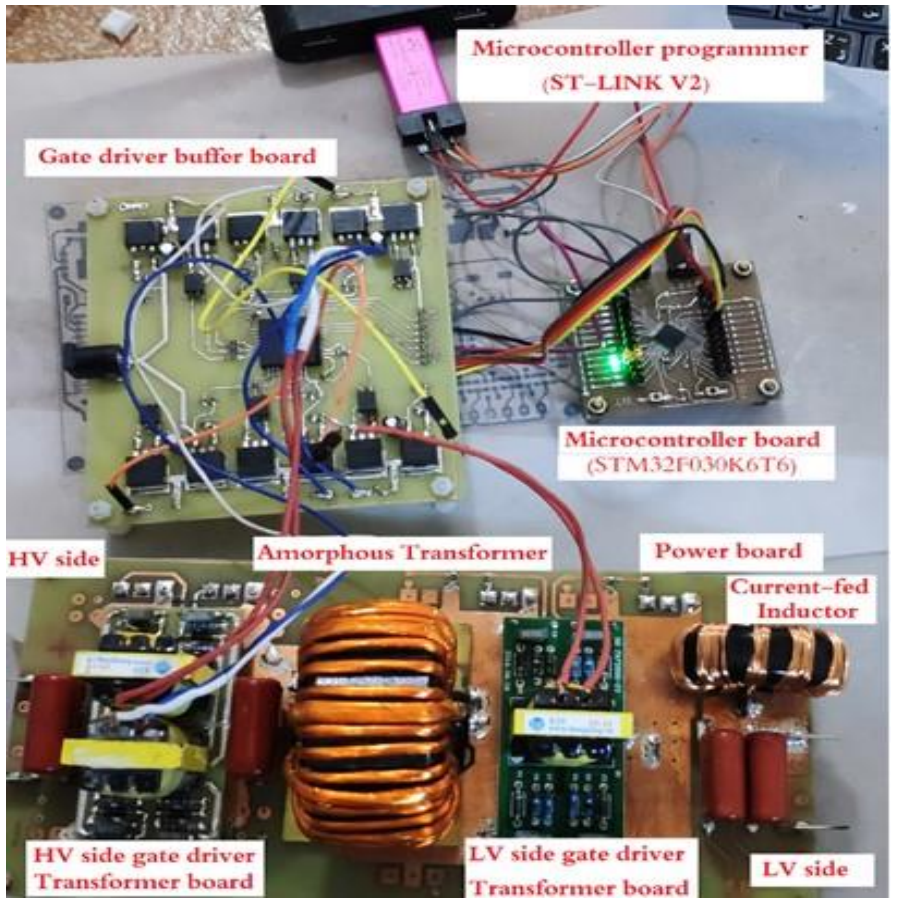

Figure 12. The final assembled system components

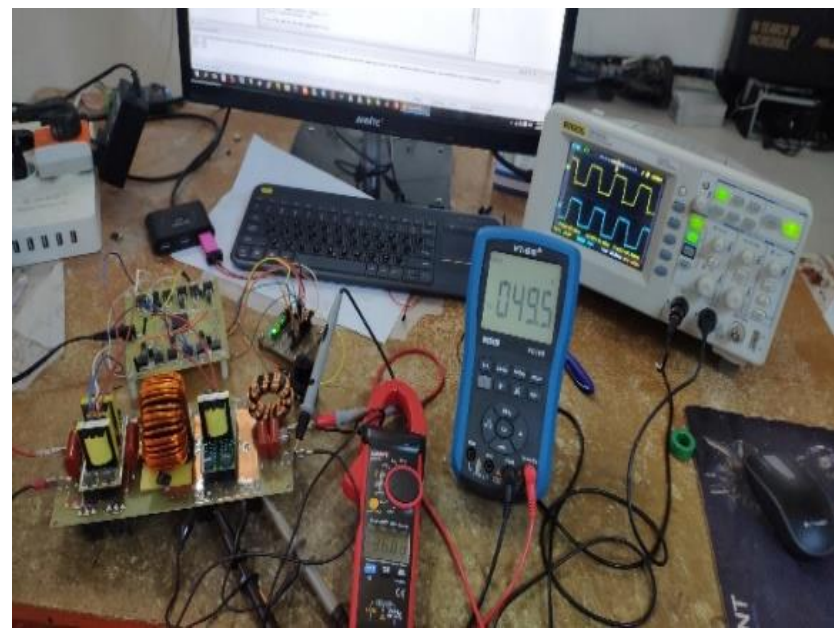

Figure 13. Screenshot of the system with measurements

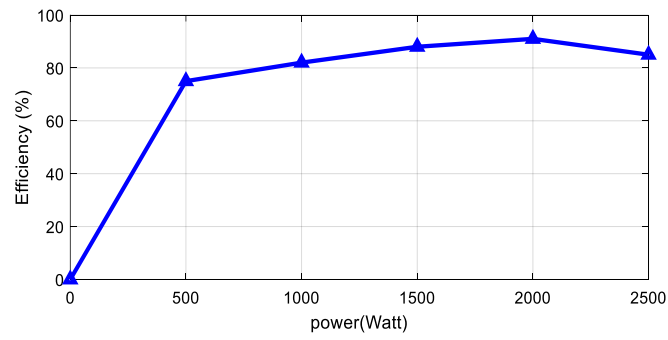

Figure 14. System efficiency vs. output power in buck mode

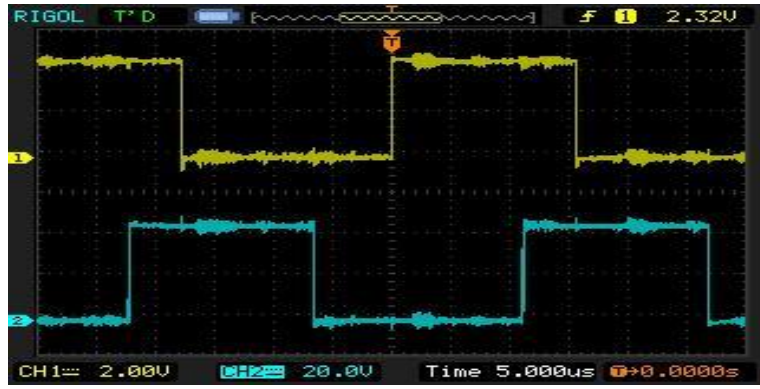

Figure 15. Complementary PWM signals with dead time 


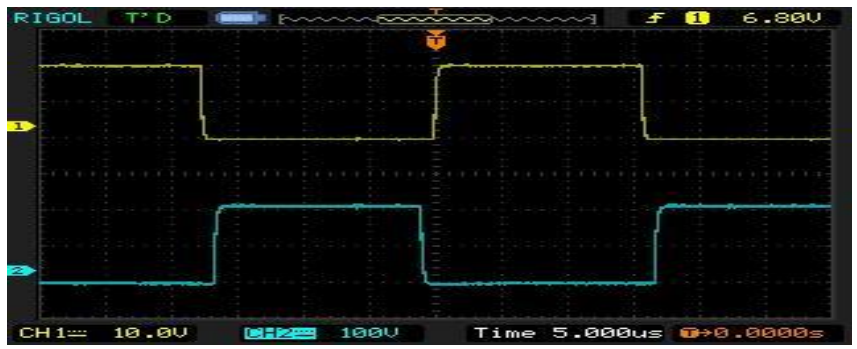

Figure 16. PWM signal after driver board

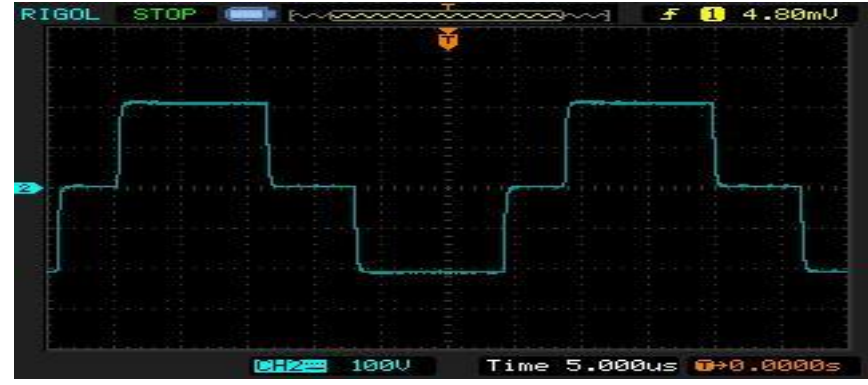

Figure 17. Voltage waveform across the transformer's primary terminals at a phase shift of 600

Table 1. Specifications of the proposed work.

\begin{tabular}{|c|c|c|c|c|c|}
\hline Parameter & $\begin{array}{l}\text { Test condition } \\
\text { Battery Char }\end{array}$ & $\begin{array}{l}\min \\
\text { de }(\mathrm{Bu}\end{array}$ & nom & $\max$ & Units \\
\hline \multicolumn{6}{|c|}{ 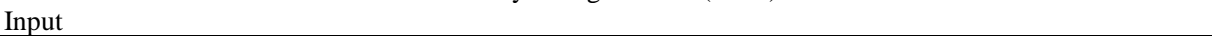 } \\
\hline Input bus voltage $\left(\mathrm{V}_{\mathrm{BUS}}\right)$ & - & 300 & 350 & 380 & $\mathrm{~V}$ \\
\hline Input bus current & - & - & - & 5 & A \\
\hline Efficiency & $\begin{aligned} \mathrm{V}_{\text {bat }} & =53.4 \mathrm{~V} \\
\mathrm{I}_{\text {bat }} & =20 \mathrm{~A}\end{aligned}$ & - & - & 88 & $\%$ \\
\hline \multicolumn{6}{|l|}{ Output } \\
\hline $\begin{array}{l}\text { Output battery voltage } \\
\left(\mathrm{V}_{\text {bat }}\right)\end{array}$ & - & 44 & 48 & 56 & V \\
\hline Output battery current $\left(\mathrm{I}_{\mathrm{bat}}\right)$ & - & - & - & 20 & A \\
\hline \multicolumn{6}{|c|}{ Backup Mode (Boost) } \\
\hline $\begin{array}{l}\text { Input } \\
\text { Innut }\end{array}$ & & & & & \\
\hline $\begin{array}{l}\text { Input battery voltage }\left(\mathrm{V}_{\mathrm{bat}}\right) \\
\text { Input battery current }\left(\mathrm{I}_{\mathrm{batmax}}\right)\end{array}$ & $\mathrm{V}_{\mathrm{bat}}=53.4 \mathrm{~V}$ & $\begin{array}{l}44 \\
-\end{array}$ & $\begin{array}{l}48 \\
-\end{array}$ & $\begin{array}{l}56 \\
50\end{array}$ & $\begin{array}{l}\text { V } \\
\text { A }\end{array}$ \\
\hline Efficiency & $\begin{aligned} \mathrm{V}_{\text {bat }} & =53.4 \mathrm{~V} \\
\mathrm{I}_{\text {bat }} & =50 \mathrm{~A}\end{aligned}$ & - & - & 92 & $\%$ \\
\hline \multicolumn{6}{|l|}{ Output } \\
\hline Output bus voltage ( $\mathrm{V}_{\text {BUS }}$ ) & $\mathrm{V}_{\text {bat }}=53.4 \mathrm{~V}$ & 300 & 350 & 380 & V \\
\hline Output bus current & & - & - & 7 & A \\
\hline
\end{tabular}

Testing the circuit with a Wi-Fi sensor as one type of IoT makes it a very powerful tool to efficiently measure the solar panel's current voltage power, as can be seen in Figure 18. A square wave is applied to the circuit to imitate repeated unit step input to the reference of $1 \mathrm{~Hz}$ at $20 \mathrm{~A}$ with full load. The desired output response with a small overshoot is obtained, as shown in Figure 19. With the same reference input but 0A, the output response is shown in Figure 20. The output voltage at $40 \mathrm{~A}$ is shown in Figure 21.

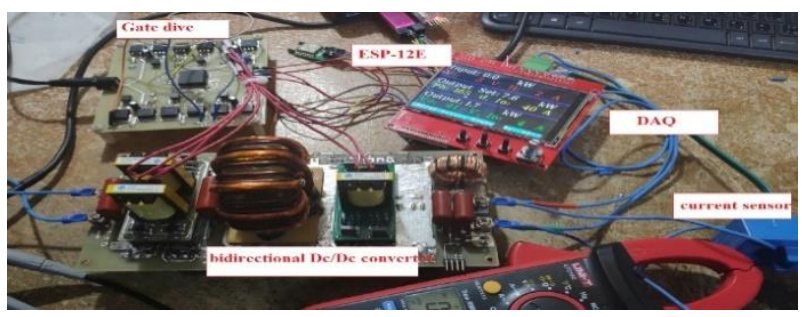

Figure 18. Complete setup with Wi-Fi capability 


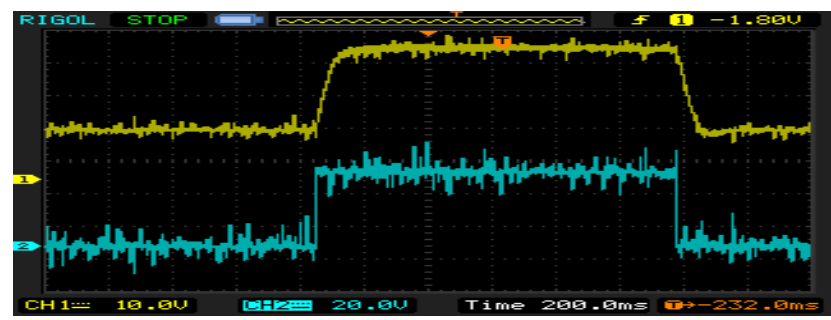

Figure 19. Output voltage with its reference input at $20 \mathrm{~A}$

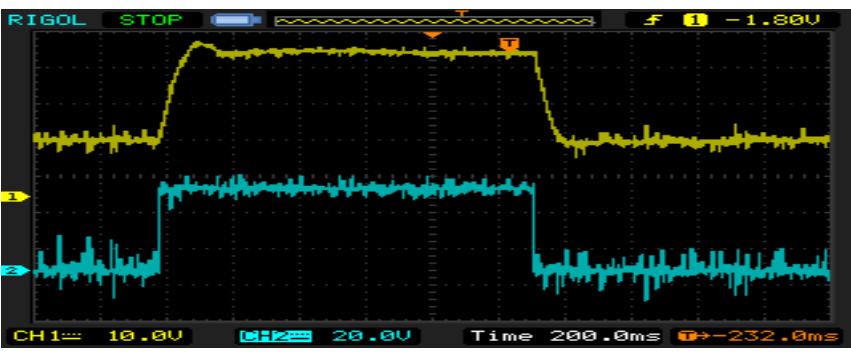

Figure 20. Output voltage with its reference input at $0 \mathrm{~A}$

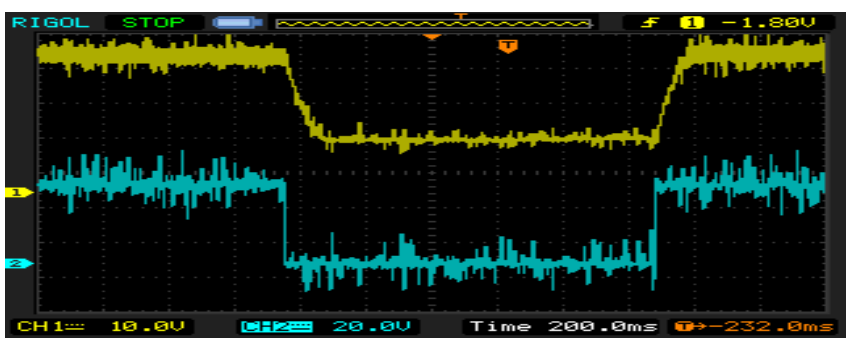

Figure 21. Output voltage with its reference input at $40 \mathrm{~A}$

In this case, $15 \%$ of overshoot is obtained at no load. For checking the effectiveness of the compete designed for a system, a comparison between the proposed converter and TIDA-BIDIR-400-12 is summarized in Table 2 [32]. This comparison explains the contribution of the proposed works with IoT technique as new and powerful tool in the communication. The communication between the bidirectional DC/DC converter and the computer can be illustrated as in Figure 22.

Table 2. Comparison between the bidirectional proposed converter and Texas instrument device

\begin{tabular}{|c|c|c|}
\hline Feature & Designed work: & TIDA-BIDIR-400-12 \\
\hline LV topology & $\begin{array}{l}\text { Full-bridge double-MOSFET for increasing the LV current } \\
\text { capability, the voltage stress on each switch is half of the } \\
\text { voltage when using push-pull topology, which means that } \\
\text { lower voltage (lower RDS_on, higher current and cheaper) } \\
\text { MOSFET's can be used. }\end{array}$ & $\begin{array}{l}\text { Two MOSFET's push-pull topologies with } \\
\text { voltages of twice as in a full-bridge topology, } \\
\text { which leads to higher } \mathrm{dV} / \mathrm{dt} \text {, dI/dt (increase } \\
\text { switching losses), lower current ratings, and } \\
\text { more expensive MOSFET's should be used. }\end{array}$ \\
\hline Gate Drivers & $\begin{array}{l}\text { Pulse transformer driver type is used for more reliable and } \\
\text { natural protection from cross conduction. Each bridge leg is } \\
\text { derived from the same transformer, but each transistor is } \\
\text { connected to a different isolated winding and opposite } \\
\text { polarity). The LV side is derived using a single four-winding } \\
\text { transformer that is controlled from the same two-PWM signals } \\
\text { that drive one of the two legs on the HV side. This means that } \\
\text { only four PWM signals are required to control both LV and } \\
\text { HV stages. }\end{array}$ & $\begin{array}{l}\text { Specific gate driver ICs are used, which } \\
\text { increases the complexity of the system. In } \\
\text { addition, 6-PWM signals are used instead of } \\
\text { four to drive HV and LV stages. Precise } \\
\text { synchronization between LV and HV PWM } \\
\text { signals is required, which leads to more CPU } \\
\text { load, unlike the designed work, which does not } \\
\text { require any synchronization because it uses the } \\
\text { same PWM signals to drive the LV side. }\end{array}$ \\
\hline Efficiency & The efficiency of the designed system is $92 \%$ & The efficiency of TI converter is $93 \%$ \\
\hline
\end{tabular}




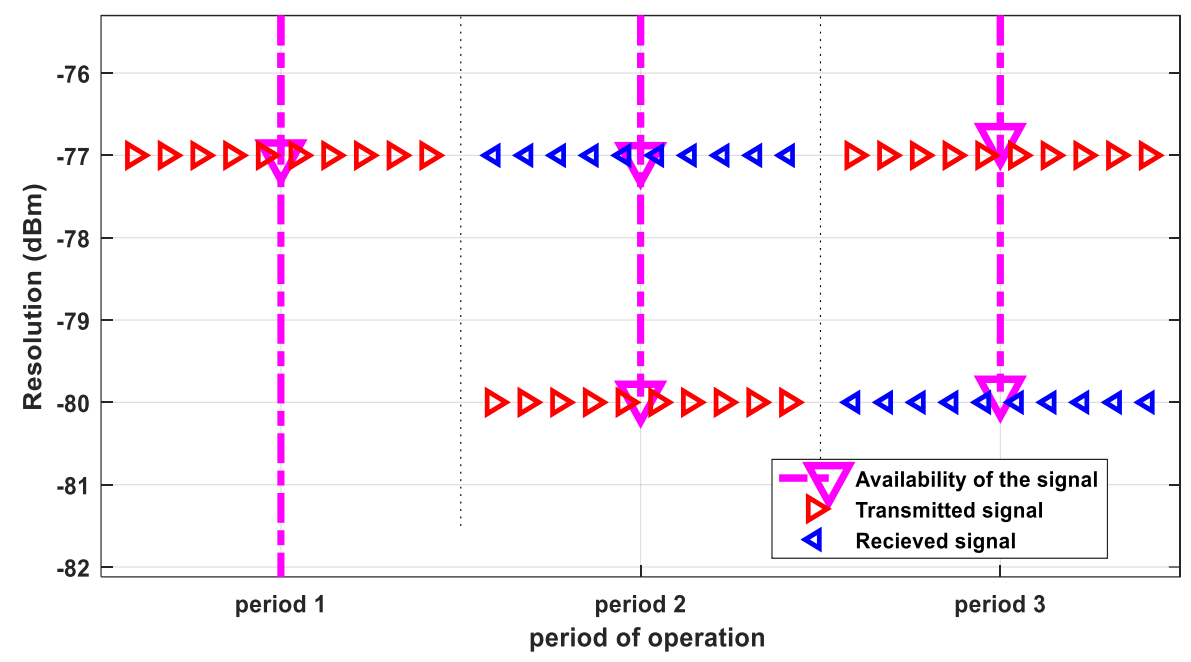

Figure 22. Communication signal monitoring

\section{CONCLUSION}

In this work, the advancements of technologies are used to build a smart and efficient bidirectional DC-DC converter-based IoT that can be controlled and monitored through a Wi-Fi network. The bidirectional DC-DC converter with IoT capabilities increased the usability of the structure in various applications. The continuous monitoring improves the performance specifications and eases the DC-DC's compensation against the failures and overarching of the battery. The microcontroller-based isolated bidirectional converter is rated for $2 \mathrm{~kW}$ of output power in either direction. The very high permeability and high saturation induction of the transformer core allow much less transformer turns as compared to the traditional transformers. This leads to decreased transformer loss, increased system efficiency, and reduced system cost and weight. By combining the amorphous cores with IGBT's, much larger power converters can be easily implemented up to tens of kilowatts. This is because the IGBT's are readily available in ratings of hundreds of amperes.

This work is primarily designed for solar energy applications and used with an inverter connected in parallel with the converter's HV side. The inverter and the bidirectional converter are powered by an HV DC bus or solar panels. This means that the inverter is always fed with high voltage either from solar panels or from designed converter. The direct conversion of the HV dc voltage to a usable AC voltage eliminates the need for a separately sold charge controller. Hence, the efficiency is increased with a considerable reduction in system cost, weight, and complexity.

\section{REFERENCES}

[1] P. Lezynski, P. Szczesniak, B. Waskowicz, R. Smolenski, and W. Drozdz, "Design and Implementation of a Fully Controllable Cyber-Physical System for Testing Energy Storage Systems," IEEE Access, vol. 7, pp. 47259-47272, 2019, doi: 10.1109/ACCESS.2019.290761.

[2] A. Homadi, T. Hall, and L. Whitman, "Using solar energy to generate power through a solar wall," Journal of King Saud University-Engineering Sciences, vol. 32, no. 7, pp. 470-477, 2020, doi: 10.1016/j.jksues.2020.03.003.

[3] A. Q. Huang "Solid-state transformers, the Energy Router and the Energy Internet," The Energy Internet, 2019, doi: 10.1016/C2016-0-04520-5.

[4] A. Bindra and T. Keim, "APEC Talks Reliability and Production of WBG Devices: Disclosing the Latest Developments in Components, Packaging, Transportation Electrification, and Renewable Energy," IEEE Power Electronics Magazine, vol. 6, no. 2, pp. 48-56, 2019, doi: 10.1109/MPEL.2019.2911439.

[5] A. Tah and N. Lakshmi, "Simple soft-switched phase-shifted FB converter for reduced voltage stress and negligible duty cycle loss," IET Power Electronics, vol. 12, no. 11, pp. 2780-2792, 2019, doi: 10.1049/iet-pel.2019.0324.

[6] X. Chen, A. A. Pise, J. Elmes, and I. Batarseh, "Ultra-Highly Efficient Low-Power Bidirectional Cascaded BuckBoost Converter for Portable PV-Battery-Devices Applications," IEEE Transactions on Industry Applications, vol. 55, no. 4, pp. 3989-4000, July-Aug. 2019, doi: 10.1109/TIA.2019.2911566.

[7] X. Chen, A. Pise, I. Batarseh, and J. Elmes, "A new adaptive switching frequency modulation for optimizing low power cascaded buck-boost converter," 2017 IEEE Energy Conversion Congress and Exposition (ECCE), 2017, pp. 4230-4236, doi: 10.1109/ECCE.2017.8096732.

[8] C. A. Iskak, N. A. Windarko, and R. Rakhmawati, "Design and Implementation Bidirectional DC-DC Converter for Load Sharing and Charging Battery," 2019 International Seminar on Application for Technology of Information and Communication (iSemantic), 2019. 
[9] I. David and F. Leon, Renewable Energy in Power Systems. Second Edition, John Wiley \& Sons, 2020.

[10] D. Ravi, B. M. Reddy, S. S. 1, and P. Samuel, "Bidirectional dc to dc Converters: An Overview of Various Topologies, Switching Schemes and Control Techniques," International Journal of Engineering \& Technology, vol. 7, no. 4.5, p. 360, 2018, doi: 10.14419/ijet.v7i4.5.20107.

[11] A. E. Aroudi, R. Haroun, M. Al-Numay, and M. Huang, "Multiple-Loop Control Design for a Single-Stage PV-Fed Grid-Tied Differential Boost Inverter," Applied Sciences, vol. 10, no. 14, p. 4808, 2020, doi: 10.3390/app10144808.

[12] F. L. Tofoli, D. D. A. Tavares, and J. I. D. A. Saldanha, "Survey on topologies based on the three-state and multistate switching cells," IET Power Electronics, vol. 12, no. 5, pp. 967-982, 2019, doi: 10.1049/iet-pel.2018.6003.

[13] G. N. B. Yadav and N. L. Narasamma, "An Active Soft Switched Phase-Shifted Full-Bridge DC-DC Converter: Analysis, Modeling, Design, and Implementation," IEEE Transactions on Power Electronics, vol. 29, no. 9, pp. 4538-4550, Sept. 2014, doi: 10.1109/TPEL.2013.2284780.

[14] M. C. G. Pérez Hernández and A. Conde Enríquez, "Impact of dynamic performance of batteries in microgrids," Distributed Energy Resources in Microgrids, Academic Press, 2019, pp. 185-214, doi: 10.1016/B978-0-12817774-7.00007-7.

[15] M. Hossain, N. Rahim, and J. A. Selvaraj, "Recent progress and development on power DC-DC converter topology, control, design and applications: A review," Renewable and Sustainable Energy Reviews, vol. 81, pp. 205-230, 2018, doi: 10.1016/j.rser.2017.07.017.

[16] H. -H. Wu, C. -H. Huang, C. -L. Wei, and J. -S. Lai, "Bidirectional Single-Inductor Dual-Supply Converter with Automatic State-Transition for IoT Applications," IEEE Transactions on Circuits and Systems I: Regular Papers, vol. 66, no. 10, pp. 4068-4078, Oct. 2019, doi: 10.1109/TCSI.2019.2913440.

[17] J. I. Leon, S. Vazquez, and L. G. Franquelo, "Multilevel converters-control and operation in industrial systems," Power Electronics in Renewable Energy Systems and Smart Grid: Technology and Applications, First Edition, Wiley, 2019, doi: 10.1002/9781119515661.

[18] K. Bhatt, R. A. Gupta, and N. Gupta, "Comparative Analysis and Control of Bidirectional DC-DC Converters," in 2019 IEEE 1st International Conference on Energy, Systems and Information Processing (ICESIP), 2019, pp. 1-6, doi: 10.1109/ICESIP46348.2019.8938349.

[19] M. Escudero, D. Meneses, N. Rodriguez, and D. P. Morales, "Modulation Scheme for the Bidirectional Operation of the Phase-Shift Full-Bridge Power Converter," IEEE Transactions on Power Electronics, vol. 35, no. 2, pp. 1377-1391, Feb. 2020, doi: 10.1109/TPEL.2019.2923804.

[20] I. Manushyn, "Design and Optimization of EMI Filters for Power Electronics Systems," Ph.D. Thesis, Department of Electrical Engineering and Information Technology, Institute for Power Electronics and Control of Drives, Technische University, Darmstadt, Germany, 2019.

[21] M. Barlow, S. Ahmed, A. M. Francis, and H. A. Mantooth, "An Integrated SiC CMOS Gate Driver for Power Module Integration," IEEE Transactions on Power Electronics, vol. 34, no. 11, pp. 11191-11198, Nov. 2019, doi: 10.1109/TPEL.2019.2900324.

[22] M. Azab, "Design approach and performance analysis of trap filter for three-phase PV grid integration systems using evolutionary search algorithms," Journal of King Saud University-Engineering Sciences, 2020, doi: 10.1016/ j. jksues.2020.06.

[23] M. S. Shaker and A. A. Kraidi, "Robust observer-based DC-DC converter control," Journal of King Saud University -Engineering Sciences, vol. 31, no. 3, pp. 238-244, 2019, doi: 10.1016/j.jksues.2017.08.002.

[24] M. Lee, C. Yeh, O. Yu, J. Kim, J. Choe and J. Lai, "Modeling and Control of Three-Level Boost Rectifier Based Medium-Voltage Solid-State Transformer for DC Fast Charger Application," IEEE Transactions on Transportation Electrification, vol. 5, no. 4, pp. 890-902, Dec. 2019, doi: 10.1109/TTE.2019.2919200.

[25] M. Pourbehzadi, T. Niknam, J. Aghaei, G. Mokryani, M. Shafie-Khah, and J. P. Catalão, "Optimal operation of hybrid AC/DC microgrids under uncertainty of renewable energy resources: A comprehensive review," International Journal of Electrical Power \& Energy Systems, vol. 109, pp. 139-159, 2019, doi: 10.1016/j.ijepes.2019.01.025.

[26] N. M Yadgar and A. H. Ahmed, "Design and implementation of Bi-directional power converter for solar energy applications," Al-Muhandis Journal, vol. 56, no. 4, pp. 7-16, 2019.

[27] N. Bizon, et al., "Hydrogen economy of the fuel cell hybrid power system optimized by air flow control to mitigate the effect of the uncertainty about available renewable power and load dynamics," Energy Conversion and Management, vol. 179, pp. 152-165, 2019, doi: 10.1016/j.enconman.2018.10.058.

[28] P. U R and A. K. Rathore, "Extended Range ZVS Active-Clamped Current-Fed Full-Bridge Isolated DC/DC Converter for Fuel Cell Applications: Analysis, Design, and Experimental Results," IEEE Transactions on Industrial Electronics, vol. 60, no. 7, pp. 2661-2672, Jul. 2013, doi: 10.1109/TIE.2012.2194977.

[29] R. M. Elavarasan, A. Ghosh, T. K. Mallick, A. Krishnamurthy, and M. Saravanan, "Investigations on Performance Enhancement Measures of the Bidirectional Converter in PV-Wind Interconnected Microgrid System," Energies, vol. 12 , no. 14, p. 2672, 2019, doi: 10.3390/en12142672.

[30] T. S. Mundra and A. Kumar, "An Innovative Battery Charger for Safe Charging of NiMH/NiCd Batteries," IEEE Transactions on Consumer Electronics, vol. 53, no. 3, pp. 1044-1052, Aug. 2007, doi: 10.1109/TCE.2007.4341584.

[31] W. Shi, Y. Guo, and Y. Liu, "When Flexible Organic Field-Effect Transistors Meet Biomimetics: A Prospective View of the Internet of Things," Advanced Materials, vol. 32, no. 15, p. 1901493, 2019, doi: 10.1002/adma.201901493.

[32] Bidirectional DC-DC Converter, Texas Instruments, TIDM-BIDIR-400-12 Design Guide (TIDUAI7), 2018. 


\section{BIOGRAPHIES OF AUTHORS}
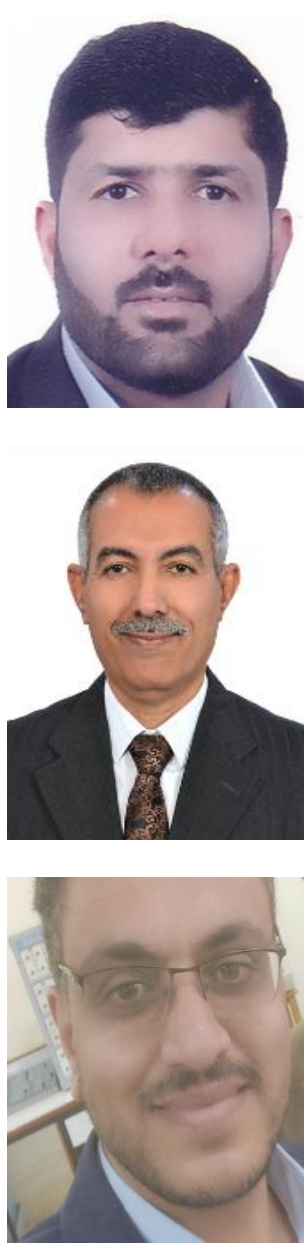

Wisam Dawood Abdullah received his B.Sc. degree in Computer Science from Tikrit University, Iraq, and his M.S. degree in Information Technology (with concentration in Telecommunications and Networks) from the University Utara Malaysia (UUM). He received an expert certification from Cisco Networking Academy CCNP, CCNA, CCNA Security, IoT, Entrepreneurship, Grid, Voice, Wireless Cloud, Linux, CCNA Cybersecurity and IT, also he is a NetAcad administrator in Cisco Networking Academy, Iraq, currently he is lecturer in the Tikrit University, Cisco Networking Academy, member in IEEE. Research interest: Protocol Engineering, Network Analysis, Internet Architecture and Technologies, Wireless Performances, Network Traffic Engineering, Data Mining, Future Internet, Internet of Things, AI, ML.

Raad Z. Homod was born in Ad Dayr Village, Basra City, in 1969. He received the B.Sc. degrees in mechanical engineering from the University of Basrah, Iraq, in 1991, He worked as a project engineer on development of HVAC control in Libya. He later completed his M.Sc. from UM and Ph.D. from UNITEN, Kuala Lumpur, Malaysia. During this period, he gained practical experience on energy and intelligent control of HVAC. He is currently the head of the department of petroleum and gas engineering at Basrah University for oil and gas, Iraq. From 1997 to 2006, he was a senior lecturer with the Sebha Vocational Intermediate Centre, Sebha, Libya. From 2007 to 2009, he was a tutor and lab demonstrator at University of Malaya and research assistant at UNITEN from 2010 to 2013. He is the author of three books, more than 20 articles, furthermore, he is a reviewer for more than 17 famous journals and $\mathrm{He}$ has awarded 4 prizes. His research interests include real time signal processing, artificial.

Abdulbasit $\mathbf{H}$ Ahmed received a B.Sc. degree in Electrical Engineering, Iraq, and he is a Master's student at the College of Engineering, Department of Electrical Engineering, Tikrit University. He has a lot of articles in this field. 